\title{
RISCOS E BENEFÍCIOS DA UTILIZAÇÃO DE SUPLEMENTOS NUTRICIONAIS NA PRÁTICA DE ATIVIDADE FÍSICA
}

\author{
RISKS AND BENEFITS OF THE USE OF NUTRITIONAL SUPPLEMENTS IN THE \\ PRACTICE OF PHYSICAL ACTIVITY
}

\author{
Karine Fino Gomes Verdan ${ }^{1}$ \\ Jéssica Ezidoro dos Santos ${ }^{2}$ \\ Vicente Antonio de Senna Junior ${ }^{3}$
}

RESUMO: Os suplementos nutricionais são produtos que tem por finalidade complementar os nutrientes que faltam na alimentação, melhoram o desempenho e nos treinos e ajudam na recuperação dos músculos. A utilização inadequada, bem como a falta de regulamentações mais rígidas interferem na segurança nutricional dos indivíduos que fazem uso dos mesmos, desta forma objetiva-se analisar os riscos da suplementação nutricional em praticantes de atividade física e o papel do farmacêutico na prática clínica, quanto a orientação e prescrição visando a prevenção, restauração e otimização da saúde física do indivíduo.

Palavras-chave: Atividade física. Atuação Farmacêutica. Suplementos nutricionais.

ABSTRACT: Nutritional supplements are products that are intended to complement the nutrients that are lacking in the diet, improve performance and training, and help with muscle recovery. The inappropriate use, as well as the lack of stricter regulations interfere in the nutritional safety of individuals who use them, in this way, the objective is to analyze the risks of nutritional supplementation in physical activity practitioners and the role of the pharmacist in clinical practice, as guidance and prescription aimed at preventing, restoring and optimizing the individual's physical health.

Keywords: Physical activity. Pharmaceutical Performance. Nutritional Supplements.

\section{INTRODUÇÃO}

Com o passar dos anos é possível perceber que a busca pela prática de atividade física tem aumentado, é através do exercício físico que se obtém melhoria de qualidade de vida, estética e consequentemente da saúde, de acordo com a Organização Mundial da Saúde, a prática de atividade física é essencial para o ser humano (WHO, 2003).

\footnotetext{
${ }^{\mathrm{I}}$ Graduação em Farmácia, Nova Iguaçu-RJ, Brasil.

${ }^{2}$ Farmacêutico, Pós-graduado em Tecnologia Industrial - Farmacêutica pela Fiocruz

${ }^{3}$ Orientador
} 
Juntamente com a prática de exercícios, é evidente a preocupação das pessoas com a melhoria da alimentação, pelos mais variados motivos, seja para obter um corpo mais magro, para auxiliar no tratamento de doenças ou para ter uma velhice mais saudável, nesse contexto, a uso de suplementos nutricionais tem sido muito utilizado pelos praticantes de atividades físicas (ALMEIDA et al., 2018).

Os suplementos nutricionais são produtos que tem por finalidade complementar a alimentação, em sua formulação há diversas vitaminas e minerais, metabólitos, aminoácidos, enzimas, ervas e botânicos, os quais dispõem de vários tipos de formulações: cápsulas de gel, em pó, comprimidos, cápsulas, ou solução líquida. Desta forma, são destinados ao aumento de massa muscular, melhoria de performance e auxiliar na perda de peso (NABUCO et al., 2016).

A Agência Nacional de Vigilância Sanitária (ANVISA) e o Departamento de Proteção e Defesa do Consumidor do Ministério da Justiça definem que os suplementos vitamínicos e minerais são produtos para complementar a dieta de pessoas saudáveis, se a ingestão de alimentos pela via oral não for suficiente. No que diz respeito às importações, a regulamentação sanitária brasileira autoriza que os indivíduos importem suplementos alimentares para consumo próprio, mesmo que esses suplementos não tenham regulamentação da ANVISA, desde que não sejam para fins de revenda ou comércio, também não podem conter componentes sujeitos a controles especiais ou não aprovadas pelo país (BRASIL, 2020).

A alimentação equilibrada e a prática de exercício físico são fatores determinantes de saúde, e a ingestão de suplementos nutricionais sem a orientação de profissionais habilitados, auto prescrição, consumo indicado por amigos são aspectos que representam um potencial risco à saúde da população (PRADO et al., 2018).

A utilização inadequada dos suplementos nutricionais, a real necessidade de suplementação, bem como a falta de regulamentações mais rígidas são condições preocupantes no que tange a eficiência dos produtos e segurança nutricional dos indivíduos que fazem uso dos mesmos (HALLAK et al., 2007).

Portanto, o consumo sem a correta orientação profissional pode desencadear alteração fisiológica renal, sobrecarga hepática, hipercalcemia, hipertermia, arritmias, doenças coronarianas e aterosclerose (PADUA, 2009). 


\section{OBJETIVO GERAL}

Analisar os riscos e benefícios da utilização de suplementos nutricionais na prática de atividade física, de forma que o profissional farmacêutico seja atuante na orientação dos riscos e benefícios como especialista e conhecedor dos componentes dos produtos.

\section{OBJETIVOS ESPECÍFICOS}

- Identificar os principais suplementos nutricionais utilizados;

- Evidenciar a importância do uso racional de suplementos;

- Apresentar os riscos e benefícios dos suplementos nutricionais;

- Demonstrar como o profissional farmacêutico pode atuar na orientação do consumo de suplementos nutricionais.

\section{METODOLOGIA}

Para a desenvolvimento descritivo deste trabalho, buscou-se por meio de uma revisão bibliográfica, utilizar como fonte de pesquisa as principais bases de dados como: literatura científica, periódicos nacionais e internacionais indexados, monografias, dissertações, teses, revistas científicas, revistas eletrônicas, Ministério da Saúde (MS), ANVISA, Google Acadêmico e Scielo (Scientific Eletronic Library Online), os quais datam do ano de 2003 a 2019. Foi escolhido preferencialmente estudos de língua portuguesa e os de língua inglesa que corroboravam com o tema.

\section{JUSTIFICATIVA}

O uso de suplementação nutricional é uma estratégia que visa melhora do desempenho durante a prática de atividade física. Nesse sentido, observa-se que praticantes de exercícios estão em busca de resultados mais rápidos em um período de tempo mais curto (SANTOS; PEREIRA, 2017).

Justifica-se nesse artigo analisar os riscos e benefícios da utilização de suplementos nutricionais por praticantes de atividade física, tendo o profissional farmacêutico como atuante na orientação de consumo dos mesmos, sendo conhecedor técnico dos componentes de tais produtos e sua atuação no organismo. 


\section{DESENVOLVIMENTO}

\section{Principais suplementos nutricionais consumidos pelos praticantes de atividade física e suas funcionalidades}

Os suplementos alimentares ou suplementos nutricionais são alimentos orais utilizados para suprir deficiências alimentares, contribuindo para um melhor desempenho pessoal ou ter mais resistência durante a prática de atividade física, os quais podem ser compostos por carboidratos, proteínas, aminoácidos, vitaminas e minerais, extratos de plantas ou pela junção desses elementos (SANTOS et al., 2019)

A alimentação é fundamental para o ganho de massa muscular, não sendo necessário a suplementação com proteínas, em contraposição, atletas de alto rendimento se beneficiam de sua utilização. Sabe-se que o principal alvo da indústria de suplementos são os praticantes de atividades físicas em academias, porém estudos expressam que os indivíduos que mais consomem suplementos são os atletas (ERDMAN et al., 2006).

A indústria produtora de suplementos teve um aumento de II\% nas vendas entre os anos de 2011 a 2019, alcançando um alto faturamento. Estima-se que a venda de suplementos tenha uma movimentação em torno de 30 bilhões de dólares por ano, e tende a crescer mais, pois a cada ano há novos praticantes de atividade física, os quais possuem necessidade de suplementar para obter os resultados almejados (SALAZAR; GARCÍA, 2019).

Um estudo conduzido por Goston e Correia (2010), menciona que jovens e indivíduos do gênero masculino que praticam de exercícios físicos consomem mais suplementos proteicos e de aminoácidos de cadeira ramificada. Froiland et al (2004), relata que as praticantes femininas com mais de 40 anos, consumiam mais vitaminas e minerais, além dos fitoterápicos, por outro lado as praticantes jovens consumiam com maior periodicidade cálcio e polivitamínicos, e os homens jovens glutamina, whey protein e aminoácidos.

Praticantes mais jovens, com menos de 30 anos suplementam na intenção de ganhar massa muscular e os que possuem mais de 45 objetivando prevenir doenças (GOSTON; CORREIRA, 2010) 
Os suplementos hidroeletrolíticos tem por finalidade repor perdas de eletrólitos que o atleta tem durante o treino, a suplementação dos isotônicos evitam desidratação e depleção do glicogênio, fonte energética armazenada no fígado (GERALDINI et al., 2017).

O consumo do carboidrato corresponde a cerca de 50\% das calorias diárias dos indivíduos, é responsável pela energia fornecida para as atividades do dia a dia e a primeira fonte energética utilizada nos treinos, a maltodextrina é um exemplo de carboidrato, sua absorção se dá mais lentamente, propiciando um melhor rendimento nos treinos de longa duração (SILVA et al., 2018).

Os hipercalóricos são suplementos compostos por carboidratos, proteínas de alto valor biológico, vitaminas e minerais, são muito consumidos por praticantes de atividades físicas e pessoas que querem aumentar o peso, assim como também podem ser utilizados para substituir refeições (FREITAS; COSTA; COSTA, 2017).

As proteínas, constituem a composição de células, tecidos, participa da fabricação de enzimas e hormônios, atua na regulação metabólica e fornece energia para as células (SÁ et al., 2015). As mais consumidas pelos praticantes de atividade física são Whey Protein (proteína do soro de leite) e albumina (clara do ovo), por possuírem alto valor biológico e a concentração de aminoácidos essenciais e de cadeia ramificada, o que auxilia numa melhor nutrição e reparação muscular ao praticante de atividade (FERREIRA et al., 2016).

A albumina é uma proteína de alto valor biológico, está presente na clara do ovo e é vendida em sua forma isolada para complementar dietas que visam o aumento de massa muscular (FREITAS; COSTA; COSTA, 2017).

Os aminoácidos essenciais são as partículas constituintes das proteínas, não são produzidos pelo organismo, sendo necessário à sua ingestão por meio da alimentação ou suplementação, são utilizados para potencializar a síntese muscular, são eles: glutamina e BCAA (leucina, valina e isoleucina) (WU, 2010).

A creatina é uma amina sintetizada naturalmente pelos rins, fígado e pâncreas, também é obtida através da alimentação, pelo consumo de carne vermelha e peixes. É encontrada livremente no organismo, nos músculos esqueléticos, cardíacos, lisos, cérebro e testículos. Tem por função aumento da força nos treinos, ação anticatabólica, antioxidante e estimula a síntese de proteínas (LIMA; BRITTO; CALVO, 2017)

As vitaminas e minerais são responsáveis por atuar na eliminação de radicais livres produzidos durante o exercício, nos treinos de alta intensidade há perdas desses 
micronutrientes no suor e na urina, dessa forma a suplementação visa corrigir inadequações nutricionais a fim de atender as recomendações diárias (FURLAM et al., 2019)

A utilização de cafeína na dosagem de 3 a $6 \mathrm{mg} / \mathrm{kg}$ de peso contribui no desempenho durante a prática do exercício, fornece mais energia, previne a fadiga e pode auxiliar na perda de peso, porém estudos relatam que a superdosagem tem por efeito sintomas como: como nervosismo, tremores, desidratação e palpitações (GOMES et al., 2014).

\section{Uso racional de suplementos nutricionais: riscos e benefícios da utilização}

A alimentação saudável e variada em conjunto com a prática de exercícios físicos, consegue suprir as necessidades diárias de micronutrientes (vitaminas e minerais) essenciais para o indivíduo, fazendo com que o corpo funcione em homeostase (ABEMATSUMOTO; SAMPAIO; BASTOS, 2015).

Porém alguns fatores podem interferir, fazendo com que seja necessária a suplementação nutricional: má alimentação, disbiose intestinal, etilismo, tabagismo, patologias (RÊGO et al., 2016). Outras razões são, estilo de vida, como por exemplo, atletas, que necessitam de uma ingestão maior de nutrientes em relação a um praticante de atividade física não atleta (STOPASSOLI, 2015).

$O$ uso de suplementos nutricionais relaciona-se com os seguintes benefícios: aumento de resistência, reduzem gordura corporal, aumento de massa muscular, minimizam o risco de doenças, recuperam os músculos ou promovem melhora no desempenho durante os exercícios físicos, porém o uso abusivo de tais substâncias que potencializam os resultados em menos tempo não são totalmente inofensivas (POSSEBON; OLIVEIRA, 20I6).

A prescrição de suplementos nutricionais é atividade privativa do nutricionista, regulamentado pela Lei Federal no 8234/91, em seu artigo $4^{\circ}$, inciso VII o qual atribui a este profissional ações relacionadas a alimentação e nutrição humana. A utilização de suplementos nutricionais pode ocasionar sobrecarga de órgãos como fígado e rins, responsáveis pela metabolização de nutrientes como proteínas e carboidratos, o excesso da ingestão desses nutrientes pode causar falência desses órgãos (KARKLE, 2015).

Vale ressaltar o papel do farmacêutico na prática clínica, a qual permite a orientação e prescrição de alguns suplementos visando a prevenção, restauração e 
otimização da saúde física e mental, bem como informar o paciente sobre a utilização e dispensação do suplemento alimentar, se julgar que o mesmo pode afetar a saúde do paciente (VENDA, 2019).

De acordo com os estudos, os danos mais comuns causados pelo uso de suplementos estão relacionados a órgãos como fígado e rins, como podemos observar no quadro abaixo (QUADRO I):

QUADRO I: Possíveis danos causados de acordo com o suplemento utilizado

\begin{tabular}{|c|c|c|c|}
\hline AUTOR & SUPLEMENTO & $\begin{array}{c}\text { DANO } \\
\text { HEPÁTICO }\end{array}$ & DANO RENAL \\
\hline Gulano et al., (2008) & Creatina & Não & Sim \\
\hline Terada et al., (2012) & Whey Protein & Sim & Sim \\
\hline Leite e Lombardi & Maltodextrina & Sim & \\
\hline (2015) & & & \\
& & & \\
\hline
\end{tabular}

FONTE: Próprio autor, 2021

Apesar dos inúmeros relatos de caso, ainda não há evidências sustentáveis que corroborem com a ideia de que a creatina seja maléfica em indivíduos gsaudáveis (Gulano et al., 2008). Já Terada et al., (2012) associou os riscos do consumo de proteína em doses acima das recomendadas a danos hepáticos e renais, além da contaminação por esteroides, que não eram discriminados nas embalagens. A suplementação a longo prazo de maltodextrina se relacionou a uma concentração elevada de glicogênio renal após exercício aeróbio contínuo (LEITE; LOMBARDI, 2015).

O excesso da utilização de vitaminas e minerais pode causar lesões a órgãos como fígado e coração, náuseas, cálculos renais e biliares, fraqueza muscular entre outros problemas (FRINHANI; LEONHARDT, 2016). 
O consumo inadequado ou uso excessivo de suplementos pode provocar diversos efeitos adversos, como a sobrecarga dos rins e do fígado, sonolência excessiva, aumento da acne, a desidratação e redução da densidade óssea e alterações cardíacas e problemas psicológicos. O consumo de proteínas acima de $15 \%$ do gasto energético total pode levar à cetose, gota, levar a sobrecarga renal, aumentar gordura visceral e propiciar balanço negativo de cálcio (DE ARAÚJO; ANDREOLO; SILVA, 2008)

A utilização desregrada de suplementos nutricionais se dá pela falta de conhecimento sobre as consequências negativas do uso abusivo, também pelo fato de muitos consumidores não procurarem um profissional habilitado para as prescrições (FONSECA et al., 2018).

\section{Atuação farmacêutica na orientação da utilização de suplementos nutricionais}

A utilização de qualquer medicamento ou suplemento por mais que pareça inofensiva, pode desencadear reações indesejáveis, desta forma o farmacêutico por estar presente nas drogarias é o profissional que está mais próximo do consumidor no ato da compra, podendo tirar dúvidas e orientar quanto ao uso correto, dado que, o uso excessivo de tais substâncias pode ocasionar problemas de saúde, seu papel é orientar os pacientes, pretendendo reduzir os riscos da utilização inadequada dos suplementos nutricionais (ABE-MATSUMOTO; SAMPAIO; BASTOS, 2015).

A assistência farmacêutica deve assegurar atendimento integral, promoção, proteção e recuperação da saúde das pessoas, seja em farmácias comunitárias, estabelecimentos de saúde, ou Sistema Único de Saúde (SUS), dessa forma compete ao farmacêutico não só a prescrição de suplementos alimentares, como também dietas especiais formuladas para necessidades especiais, produtos apícolas (mel, própolis, geleia real), além de manipulações funcionais, prescrito por profissional habilitado, com forma farmacêutica, composição e posologia estabelecidos (BRASIL, 2018)

No que concerne as práticas relacionadas à Farmácia Clínica, a atuação do farmacêutico no cuidado ao paciente que utiliza suplementação pode contribuir com a manutenção e recuperação da saúde do mesmo, a atuação do farmacêutico na prescrição de suplementos é regida pela resolução de número 661/2018 do Conselho Federal de Farmácia (BRASIL, 2018).

No quadro 2, logo abaixo veremos as etapas de atuação do profissional farmacêutico na suplementação nutricional. 


\section{QUADRO 2: ATUAÇÃO FARMACÊUTICA NA SUPLEMENTAÇÃO}

\section{NUTRICIONAL}

\begin{tabular}{|c|c|}
\hline ETAPAS & Atividades Clínicas \\
\hline $\begin{array}{c}\text { Consulta } \\
\text { Farmacêutica/ } \\
\text { Serviços } \\
\text { Farmacêuticos }\end{array}$ & $\begin{array}{l}\text { - Prover a consulta em consultório farmacêutico ou em outro ambiente } \\
\text { adequado que garanta a privacidade do atendimento; } \\
\text { - Fazer a anamnese farmacêutica e verificar sinais e sintomas com o } \\
\text { propósito de prover cuidado ao indivíduo; } \\
\text { - Solicitar exames laboratoriais no âmbito de sua competência para } \\
\text { monitorar os resultados da terapia, inclusive medicamentosa; } \\
\text { - Avaliar resultados de exames clínico-laboratoriais para auxiliar na } \\
\text { individualização da terapia, inclusive medicamentosa; } \\
\text { - Monitorar níveis terapêuticos de medicamentos ora em uso, por } \\
\text { meio de dados de farmacocinética clínica; } \\
\text { - Determinar parâmetros bioquímicos e fisiológicos, para fins de } \\
\text { acompanhamento terapêutico e rastreamento em saúde }\end{array}$ \\
\hline & $\begin{array}{l}\text { - Selecionar e documentar as terapias; } \\
\text { - Considerar as necessidades relativas ao paciente, as evidências } \\
\text { científicas de eficácia e segurança, a conveniência, e a relação do custo } \\
\text { com estas variáveis, não podendo prescrever doses ou apresentações } \\
\text { não configuradas como isentas de prescrição pela legislação sanitária } \\
\text { vigente; } \\
\text { - Considerar a importância do trabalho interdisciplinar com outros } \\
\text { profissionais de saúde, sempre que julgar necessário, realizando o } \\
\text { encaminhamento do indivíduo a outros profissionais de saúde, para } \\
\text { atendimento de demandas de maior complexidade ou especificidade; }\end{array}$ \\
\hline
\end{tabular}


- Poderá prescrever suplementos alimentares, alimentos para fins especiais, chás, produtos apícolas, alimentos com alegações de propriedade funcional ou de saúde, medicamentos isentos de prescrição e as preparações magistrais formuladas com nutrientes, compostos bioativos isolados de alimentos, probióticos e enzimas, nos seguintes contextos:

a. Para prevenção de doenças e de outros problemas de saúde;

b. Para recuperação da saúde, sempre que no processo de rastreamento houver identificação de riscos;

c. Na otimização do desempenho físico e mental, associado ao exercício físico ou não;

d. Na complementação da farmacoterapia, como forma de potencializar resultados clínicos de medicamentos, bem como prevenir ou reduzir reações adversas a medicamentos;

e. Na manutenção ou melhora da qualidade de vida.

- Analisar a prescrição de medicamentos quanto aos aspectos legais e técnicos;

- Avaliar a prescrição e informar por escrito ou verbalmente ao indivíduo e/ou a seu cuidador sobre a utilização racional do produto, industrializado ou manipulado. Deverá considerar:

a. Reações adversas potenciais;

Avaliação do b. Interações potenciais com alimentos, suplementos, medicamentos, receituário ou no exames complementares e doenças;

autocuidado

c. Toxicidade aguda, subcrônica e crônica;

d. Precauções, advertências no uso e contraindicações;

e. Modo de uso relacionado à indicação/alegação de uso; 
f. Características do indivíduo (biológicas, socioeconômicas, culturais, psicológicas e valores).

- Avaliar a necessidade de uso do produto com base nas características Dispensação do indivíduo, em evidências científicas quanto aos possíveis efeitos benéficos e/ou danosos à saúde, da conveniência do uso e custo.

- Notificar os profissionais de saúde, os órgãos sanitários competentes e o fabricante, sobre os efeitos colaterais, as reações adversas, as intoxicações (voluntárias ou não) observados e registrados na prática da nutrivigilância;

- Estabelecer protocolos de nutrivigilância para assegurar o seu uso

Vigilância nutricional ou racionalizado, a sua segurança e a sua eficácia terapêutica;

Nutrivigilância - Prestar orientação farmacêutica, com vistas a esclarecer ao paciente a relação benefício e risco, a conservação e a utilização de suplementos alimentares e demais categorias de alimentos, bem como suas interações (fármaco-nutriente, nutriente-nutriente) e a importância do seu correto manuseio.

FONTE: BRASIL, 2018

\section{CONCLUSÃO}

Os suplementos nutricionais fazem parte da rotina dos praticantes de atividade física, embora não seja necessário que todo indivíduo utilize, ficou evidente que atletas e pessoas que praticam atividades de alto rendimento fazem uso para melhorar a performance e resistência durante os treinos ou para uma melhor recuperação muscular pós treino.

Diante desse exposto, o consumo excessivo desses suplementos pode trazer consequências deletérias, sendo recomendado que o indivíduo que faz uso desses produtos seja orientado por profissional habilitado

É válido ressaltar a importância da equipe multiprofissional, visando a integridade do atendimento ao paciente, onde cada profissional atuará contribuindo com sua especificidade, médicos, nutricionistas, educadores físicos e os farmacêuticos. 
Conclui-se que o profissional farmacêutico pode contribuir com o uso racional desses produtos, uma vez que eles são vendidos também nas farmácias e drogarias onde esse profissional é responsável técnico.

\section{REFERÊNCIAS}

A WORLD HEALTH ORGANIZATION, (WHO). Diet, nutrition and the prevention of chronic diseases. World Health Organ. Tech. Rep. Serv. v. 916. p. I-8. 2003.

ABE-MATSUMOTO, L. T.; SAMPAIO, G. R.; BASTOS, D. H M. Suplementos vitamínicos e/ou minerais: regulamentação, consumo e implicações à saúde. Caderno Saúde Pública, Rio de Janeiro, v. 31, n. 7, p. 1371-138o, jul.2015.

ALMEIDA, I.V.A.; RIBEIRO, M.C.O.; FREITAS, R. Uso de suplementos alimentares e fatores associados em praticantes de atividade física de alta intensidade. Revista Brasileira de Nutrição Esportiva, São Paulo, v.ı2, n. 76, Supl. 2, p.992-ıoo4. Jan./Dez. 2018.

BRASIL. Agência Nacional de Vigilância Sanitária. Alerta aos consumidores: fique atento com os "suplementos alimentares", 2020. Disponível em: https://www.gov.br/anvisa/ptbr/assuntos/alimentos/suplementos-alimentares. Acesso em 27 Set 202I

BRASIL 2018. Ministério da Saúde. Conselho Federal de Farmácia. Resolução $n^{\circ}$ 66r, de 25 de outubro de 2018. Dispõe sobre cuidados farmacêuticos relacionados a suplementação alimentar e demais categorias de alimentos. Diário Oficial da União, Brasília, n. 2ıo, Seção I. p. 122, 31 out. 2018.

DE ARAÚJO, Leandro Rodrigues; ANDREOLO, Jesuíno; SILVA, Maria Sebastiana. Utilização de suplemento alimentar e anabolizantes por praticantes de musculação nas academias de Goiânia-GO. Revista Brasileira de Ciência e Movimento, v. Io, n. 3, p. 13-18, 2008.

ERDMAN, K. A., FUNG, T. S., \& REIMER, R. A. Influence of performance level on dietary supplementation in elite Canadian athletes. Medicine and science in sports and exercise, v. 38, n. 2, p. 349-356. 2006.

FERREIRA, G. G.; BUENO, J. C.; SOUZA, T. C.; ALVES, R. D. M. Comparação do valor nutricional segundo o rótulo e do preço de suplementos para ganho de massa muscular. Revista Científica Univiçosa, Viçosa, v. 8, n. I, p.244-25ı, dez. 2016. 
FONSECA, C.; VELOSO, H.J.; FREITAS, M. Conhecimento acerca da alimentação saudável e consumo de suplementos alimentares por praticantes do treinamento funcional. Revista Brasileira de Nutrição Esportiva, São Paulo. v. 12. n. 74. p.757-765. Nov./Dez. 2018 FREITAS, I. K. P. C.; COSTA, J. L.; COSTA, C. L. S. Suplementação Esportiva: Levantamento dos Suplementos mais Vendidos em Teresina-PI e Avaliação de Composição. Revista Saúde em Foco, v. 4, n. 2, p.129-I48, 2017.

FRINHANI, T. O.; LEONHARDT, V. Consumo de suplementos alimentares enriquecidos de vitaminas e minerais, e/ou suplemento vitamínico-mineral em uma universidade privada de Brasília-DF. Revista Brasileira de Nutrição Esportiva, São Paulo, v. Io, n. 6o, p.654-659, dez. 2016.

FROILAND, K., KOSZEWSKI, W., HINGST, J., \& KOPECKY, L. Nutritional supplement use among college athletes and their sources of information. International journal of sport nutrition and exercise metabolism, v. I4, n. I, p. 104-120. 2004.

FURLAN, A. A. C.; JUNQUEIRA-FRANCO, M. V. M.; OliVEIRA, J. C. S.; FAVARIS, J. W. S.; MARCHINI, J. S.; CUNHA, S. F. C. Desnutrição grave após cirurgia bariátrica e manifestações clínicas de infecção. Revista Associação Médica Brasileira, São Paulo, v. 65, n. 9, p. II5I-II55, set. 2019.

GERAldini, S.; CRUZ, I. F.; ROMERO, A.; FONSECA, F. L. A.; CAMPOS, M. P. Suplemento hidroeletrolítico favorece reidratação e diminui proteinúria pós-treino em atletas karate. Brazilian Journal Of Nephrology, v. 39, n. 4, p.362-369, mar. 2017.

GOMES, C.B.V.; BARRETO, A. F. C. S.; AlMEIDA, M. M.; MELlO, A. O. T.; IDE, B. N.; SANTOS, C. P. C. Uso de suplementos Termogênicos à base de cafeína e fatores associados a qualidade de vida relacionada à saúde em praticantes de atividade física. Revista Brasileira de Prescrição e Fisiologia do Exercício, São Paulo, v. 8, n. 49, p. 695-704, Set./Out. 2014.

GOSTON, J. L., \& CORREIA, M. I. T. D. Intake of nutritional supplements among people exercising in gyms and influencing factors. Nutrition, v. 26, n. 6, p. 604-611. 2010. HALLAK, A.; FABRINI, S.; PELUZIO, M.C.G. Avaliação do consumo de suplementos nutricionais em academias da zona sul de Belo Horizonte-MG, Brasil, Revista Brasileira de Nutrição Esportiva. São Paulo. Vol. ı. Núm. 2. p. 55-6o. 2007.

KARKLE, M.B. Uso de suplemento alimentar por praticantes de musculação e sua visão sobre o profissional nutricionista na área de nutrição esportiva em uma academia no 
município de Braço do Norte-SC. Revista Brasileira de Nutrição Esportiva, v. 9, n. 53, p. $447-453,2015$.

LIMA, L. R. B.; BRITTO, R. M.; CALVO, F. Efeitos do uso da suplementação com creatina em praticantes de atividades de resistência: revisão bibliográfica. Revista Saber Específico, Porto Velho, p.1-7, 2017.

NABUCO, H.; RODRIGUES, V.; RAVAGNANI, C. Fatores associados ao uso de suplementos alimentares entre atletas: Revisão Sistemática. Revista Brasileira Medicina do Esporte, v.22, n.5, Set/Out, 2016.

PADUA, Thais. $O$ risco do uso indisciplinado de suplementos alimentares. 2009. Disponível em http://www.saude.com.br/site/materia.asp?cod_materia $=427$ Acesso em: I9 Set 2021.

POSSEBON, J.; OLIVEIRA, V. Consumo de suplementos na atividade física: uma revisão. Disciplinarum Scientia| Saúde, v. 7, n. I, p. 71-82, 2016.

PRADO, L. et al. Avaliação da ingestão proteica em indivíduos frequentadores de academia. Revista Brasileira De Nutrição Esportiva, v. I2, n. 70, p. 229-237, 2018.

RÊGO, C.; NAZARETH, M.; LOPES, C.; GRAÇA, P.; PINTO, E. Suplementação Vm itamínica e Mineral em Portugal Durante o Primeiro Ano de Vida. Resultados do EPACI Portugal 2012. Acta Pediátrica Portuguesa, Porto, v. 47, p.211-220, 2016.

SÁ, C. A. G.; BENNEMANN, G. D.; SILVA, C. C.; FERREIRA, A.J. C. Consumo alimentar, ingestão hídrica e uso de suplementos proteicos por atletas de jiu-jitsu. Revista Brasileira de Nutrição Esportiva, São Paulo, v. 9, n. 53, p.4II- 4I8, out. 2015.

SALAZAR, A. S.; GARCÍA, A. M. C. Suplementos nutricionales en la industria del fitness. Revista de Nutrición Clínica y Metabolismo, v. 2, n. 2, p.6o-66, 2019.

SANTOS, E.A.; PEREIRA, F.B. Conhecimento sobre suplementos alimentares entre praticantes de exercício físico. RBNE-Revista Brasileira de Nutrição Esportiva, v. II, n. 62, p. 134-140, 2017 .

SANTOS, J.R.M.P. et al. Importância de uma regulamentação específica com as definições e classificações dos produtos comercializados como suplementos alimentares, alimentos funcionais e nutracêuticos. Revista de Direito Sanitário, v. 19, n. 3, p. 54-67, 2019. SILVA, M. A.; SARON, M. L. G.; SOUZA, C. A.; SOUZA, E. B. Avaliação dos efeitos da ingestão prévia de carboidratos sobre a resposta glicêmica de praticantes de musculação. Revista Brasileira de Nutrição Esportiva, São Paulo, v. I2, n. 76, p.ıoI-1oı, dez. 2018. 
STOPASSOLI, A. O uso da proteína do soro de leite como suplemento nutricional por atletas. Facider Revista Científica, v. 08, p.or-20, 20 is

VENDA, M.J.F. Suplementos ergogênicos e probióticos: O Papel Do Farmacêutico Comunitário. Universidade de Coimbra. 2019

WU, G. Functional Amino Acids in Growth, Reproduction, and Health. Advances In Nutrition, v. I, n. I, p.31-37, 2010. 